\title{
MUC4 expression is a novel prognostic factor in patients with invasive ductal carcinoma of the pancreas
}

\author{
M Saitou, M Goto, M Horinouchi, S Tamada, K Nagata, T Hamada, M Osako, S Takao, S K Batra, \\ T Aikou, K Imai, S Yonezawa
}

J Clin Pathol 2005;58:845-852. doi: 10.1136/icp.2004.023572

See end of article for authors' affiliations

.....................

Correspondence to: Dr S Yonezawa, Department of Human Pathology, Field of Oncology, Kagoshima University Graduate School of Medical and Dental Sciences, 8-35-1 Sakuragaoka, Kagoshima 890-8544, Japan; syoneza@m2.kufm. kagoshima-u.ac.jp

Accepted for publication 15 December 2004
Background: Many patients with invasive ductal carcinoma of the pancreas (IDC) have a poor outcome. MUC4 expression has been implicated as a marker for diagnosis and progression of IDC, but there are no studies of the relation between MUC4 expression and patient prognosis in IDC.

Aims: To investigate the prognostic significance of MUC4 expression in IDC.

Methods: The expression profiles of MUC4, ErbB2, p27, and MUC1 were investigated in IDC tissues from 135 patients by means of immunohistochemistry.

Results: MUC4 was expressed in 43 of the 135 patients with IDC (31.9\%). The survival of 21 patients with high MUC4 expression ( $>20 \%$ of neoplastic cells stained) was significantly worse than that of the 114 patients with low MUC4 expression ( $<20 \%$ of neoplastic cells stained) ( $p=0.0043$ ). Univariate analysis showed that high MUC4 expression $(p=0.0061)$, large primary tumour status $(>T 2)(p=0.0436)$, distant metastasis ( $p=0.0383$ ), lymphatic invasion ( $p=0.0243)$, and surgical margins $(p=0.0333$ ) were significant risk factors affecting the outcome of patients with IDC. Backward stepwise multivariate analysis showed that MUC4 expression ( $p=0.0121)$, lymph node metastasis ( $p=0.0245)$, and lymphatic invasion $(p=0.0239$ ) were significant independent risk factors. ErbB2, p27, and MUC1 were not independent risk factors.

Conclusions: This study shows that MUC4 expression in IDC is a new independent factor for poor prognosis and predicts the outcome of patients with IDC. l nvasive ductal carcinoma of the pancreas (IDC) still has a relatively poor prognosis. In Japan, IDC is the fifth cause of carcinoma related death in men and the sixth cause of carcinoma related death in women. ${ }^{1}$ The overall five year survival rate for all patients with or without pancreatectomy after diagnosis is $9.7 \%$ in Japan, whereas those patients with a successful resection of IDC at the early stage (stage Ia) have a $39.9 \%$ five year survival rate. ${ }^{2}$ Most patients are diagnosed in the advanced stages because of the anatomical location of the pancreas, lack of specific symptoms, infiltration to the surrounding organs, or distant metastasis even from a small primary tumour less than $2 \mathrm{~cm}$ in diameter. ${ }^{3}$

"MUC4 expression is a novel predictor of poor prognosis in patients with intrahepatic cholangiocarcinoma, mass forming type ${ }^{\prime \prime}$

Mucins are high molecular weight glycoproteins with oligosaccharides attached to serine or threonine residues of the mucin core protein backbone by $O$-glycosidic linkages, which are produced by various epithelial cells. Core proteins for human mucins (MUC1-9, MUC11-13, and MUC15-17) have been identified. ${ }^{4-11}$ Mucins are categorised into: membrane associated mucins (MUC1, MUC3, MUC4, MUC12, and MUC17), gel forming mucins (MUC2, MUC5AC, MUC5B, and MUC6), and soluble mucin (MUC7). ${ }^{12}$ Our previous studies have shown that the expression of MUCl is related to the invasive proliferation of tumours and poor patient outcome, whereas the expression of MUC2 is related to non-invasive proliferation of tumours and favourable outcome. ${ }^{43-18}$ In pancreatic tumours, IDC showed high expression of various glycoforms of MUC $1 .{ }^{4}{ }^{19}$ In contrast, the "dark cell type" and "clear cell type" of intraductal papillary mucinous neoplasms showed different expression patterns of glycosylated MUC1 and MUC2. ${ }^{19}$
MUC4 was first reported as tracheobronchial mucin, ${ }^{20}$ and has been shown to be expressed in various normal human tissues, ${ }^{21-24}$ but not in the normal pancreas. ${ }^{25}{ }^{26}$ In contrast, MUC4 expression has been detected in IDC..$^{25-28}$ Recently, Swartz et al reported that MUC4 expression increases progressively in pancreatic intraepithelial neoplasia (PanIN). ${ }^{29} 30$

In addition, MUC4 is not expressed in the normal biliary epithelium but it is expressed in cholangiocarcinoma. ${ }^{31}$ We reported for the first time that MUC4 expression is a novel predictor of poor prognosis in patients with intrahepatic cholangiocarcinoma, mass forming type (ICC-MF). ${ }^{32}$

To date, no studies are available on the relation between the expression of MUC4 and the outcome of patients with IDC. The aims of our study were to investigate the expression profile of MUC4 in IDC and to evaluate the relation between MUC4 expression and patient outcome.

The transmembrane subunit of MUC4 acts as an intramembrane ligand for the receptor tyrosine kinase ErbB2. ${ }^{33-35}$ MUC4 plays an important role in cell proliferation and differentiation of epithelial cells ${ }^{34}$ by inducing specific phosphorylation of ErbB2 and enhancing expression of the cyclin dependent kinase inhibitor p27, which inhibits cell cycle progression through the control of the Gl to S phase. ${ }^{36-38}$ Thus, we also examined the expression of ErbB2 and p27 in IDC and compared it with MUC4 expression. For comparison, we also examined MUCl expression, which has previously been reported as a useful prognostic factor in various carcinomas. ${ }^{18} 323940$

Abbreviations: $A B C$, avidin-biotinylated horseradish peroxidase complex; $\mathrm{Cl}$, confidence interval; HR, hazard ratio; ICC-MF, intrahepatic cholangiocarcinoma mass forming type; IDC, invasive ductal carcinoma of the pancreas; PanIN, pancreatic intraepithelial neoplasia; PBS, phosphate buffered saline; SMC, sialomucin complex. 
Table 1 Correlation between MUC4, ErbB2, p27, and $\mathrm{MUC1}$ expression in 135 patients with invasive ductal carcinoma of the pancreas

\begin{tabular}{clllll}
\hline & \multicolumn{3}{l}{ MUC4 expression } & & \\
\cline { 2 - 6 } & - & + & + & ++ & p Value \\
\hline ErbB2 expression & & & & & \\
- & 59 & 14 & 7 & 9 & 0.7595 \\
+ & 12 & 5 & 1 & 0 & \\
++ & 16 & 2 & 2 & 1 & \\
+++ & 5 & 1 & 1 & 0 & \\
p27 expression & & & & & \\
- & 52 & 15 & 1 & 5 & 0.0604 \\
+ & 9 & 1 & 4 & 1 & \\
++ & 15 & 3 & 4 & 1 & \\
+++ & 16 & 3 & 2 & 3 & \\
MUC1 expression & & & & \\
- & 16 & 3 & 0 & 0 & 0.5999 \\
+ & 14 & 2 & 2 & 2 & \\
++ & 27 & 9 & 3 & 2 & \\
+++ & 35 & 8 & 6 & 6 & \\
\hline
\end{tabular}

The $p$ values were assessed by means of $\chi^{2}$ test.

\section{MATERIALS AND METHODS \\ Tissue samples}

One hundred and thirty five patients (89 men, 46 women) with surgically resected IDC were retrieved from the files in Kagoshima Medical Association Hospital and Kagoshima University Graduate School of Medical and Dental Sciences (Surgical Oncology and Digestive Surgery), Japan. The mean age of the patients was 65.8 years (range, 30-82). Surgical procedures were as follows: 88 patients were treated by conventional pancreatoduodenectomy, 31 were treated by pylorus preserving pancreatoduodenectomy, 10 were treated by distal pancreatectomy, and six were treated by total pancreatectomy. The 135 cases of IDC were histologically classified according to the TNM postsurgical histopathological classification..$^{41}$ The study was approved by the Kagoshima University Graduate School of Medical and Dental Sciences human investigation committee.

The survival period after surgical resection was used as survival time for statistical analysis. The median length of the survival time at the last follow up of the patients was 11.0 months (range, 0-155). Seven patients died in the perioperative period. Clinical outcome data were available in all 135 patients with IDC, and overall survival was analysed. All the specimens were fixed in formalin, embedded in paraffin wax, and cut into $4 \mu \mathrm{m}$ thick sections for immunohistochemistry, in addition to the usual haematoxylin and eosin staining.

\section{Immunohistochemistry} Antibodies

Immunohistochemistry was carried out using the following antibodies. MUC4 was detected by a mouse monoclonal antibody, clone $8 \mathrm{G} 7 .^{30}$ ErbB2 was detected by rabbit polyclonal antibody (Dako Cytomation, Glostrup, Denmark). p27 was detected by mouse monoclonal antibody NCL-p27 (Novocastra, Newcastle, UK). MUCl was detected by mouse monoclonal antibody DF3 (mouse IgG; Toray-Fuji Bionics, Tokyo, Japan),

Biotinylated affinity purified horse antimouse IgG, goat antirabbit IgG, and avidin-biotinylated horseradish peroxidase $(\mathrm{ABC})$ complex were purchased from Vector Laboratories (Burlingame, California, USA) as the Vectastain Elite ABC kit.

\section{Staining procedure}

Immunohistochemical staining was performed with an immunoperoxidase method using the $\mathrm{ABC}$ complex as described previously. ${ }^{14} 151732$ Each section was dewaxed with xylene. Endogenous peroxidase was blocked by incubating the sections in $0.3 \%$ hydrogen peroxidase in absolute methanol at room temperature for 30 minutes. After hydration in decreasing concentrations of ethanol in water, the sections were washed in $0.01 \mathrm{M}$ phosphate buffered saline (PBS), pH 7.4. Antigen retrieval was achieved by waterbath pretreatment at $80^{\circ} \mathrm{C}$ for 20 minutes in $0.01 \mathrm{M}$ citrate buffer ( $\mathrm{pH}$ 6.0) for MUC4, waterbath pretreatment at $98^{\circ} \mathrm{C}$ for 40 minutes for ErbB2, and autoclave pretreatment at $120^{\circ} \mathrm{C}$ for five minutes for $\mathrm{p} 27$. The sections were washed twice with PBS and 2\% horse or goat serum in PBS was applied for 30 minutes at room temperature to prevent non-specific staining. The sections were then incubated with dilutions of the primary antibodies (anti-MUC4, 1/3000; anti-ErbB2, 1/100; anti-p27, 1/ 40; and anti-MUC1, 1/10) in PBS with $1 \%$ bovine serum albumin for 16 hours at $4^{\circ} \mathrm{C}$. The sections were washed three times with PBS, incubated with the biotinylated secondary antibodies, and then washed three times with PBS. All sections then received ABC complex for 30 minutes. After washing with PBS three times, the sections were finally reacted with diaminobenzidine substrate for 10 minutes for visualisation, rinsed with tap water, counterstained with haematoxylin, and mounted. Reaction products were not present when non-immune serum or PBS was used instead of the primary antibodies.

\section{Evaluation of the results by scoring}

The results of the immunohistochemical staining were evaluated as the percentage of positively stained neoplastic cells. For MUC4, ErbB2, and MUC1, membranous and cytoplasmic immunoreactivity was evaluated. For p27, nuclear immunoreactivity was evaluated. According to our previous studies, ${ }^{14}{ }^{32}$ the percentages of positively stained neoplastic cells were graded as follows:,$-<5 \%$ of neoplastic cells stained;,$+>5 \%$ but $<20 \%$ of neoplastic cells stained; ,$++>20 \%$ but $<50 \%$ of neoplastic cells stained; and +++ , $>50 \%$ of neoplastic cells stained.

In addition, for statistical analysis, the 135 cases were divided into two groups: the low expression group, composed of the - and + cases (under $20 \%$ of neoplastic cells stained), and the high expression group, composed of the ++ and +++ cases (more than $20 \%$ of neoplastic cells stained). ${ }^{14}$

\section{Statistical analysis}

Statistical analysis was performed using the Student's $t$ test, the $\chi^{2}$ test, and the Mann-Whitney U test where appropriate. Survival of the patients was compared between the group with high MUC4, ErbB2, p27, or MUCl expression, and the group with low expression. Univariate and multivariate survival analyses were performed using the Cox proportional hazards regression model. For the multivariate model, we used 0.20 as the cutoff $\mathrm{p}$ value to select the analysed factors from the univariate analysis data. Furthermore, backward stepwise multivariate analysis was used to find independent prognostic factors. A value of $p<0.05$ was considered significant.

\section{RESULTS}

\section{MUC4, ErbB2, p27, or MUC1 expression in normal} pancreatic tissue

MUC4 and ErbB2 were not expressed in normal pancreatic tissue (fig 1A). p27 was expressed in the nuclei of most normal epithelia. MUCl was expressed in the cell apices of the centroacinar cells, intercalated ducts, and intralobular ducts and focally in the interlobular ducts, but was not expressed in the main pancreatic ducts, acini, or islets. 


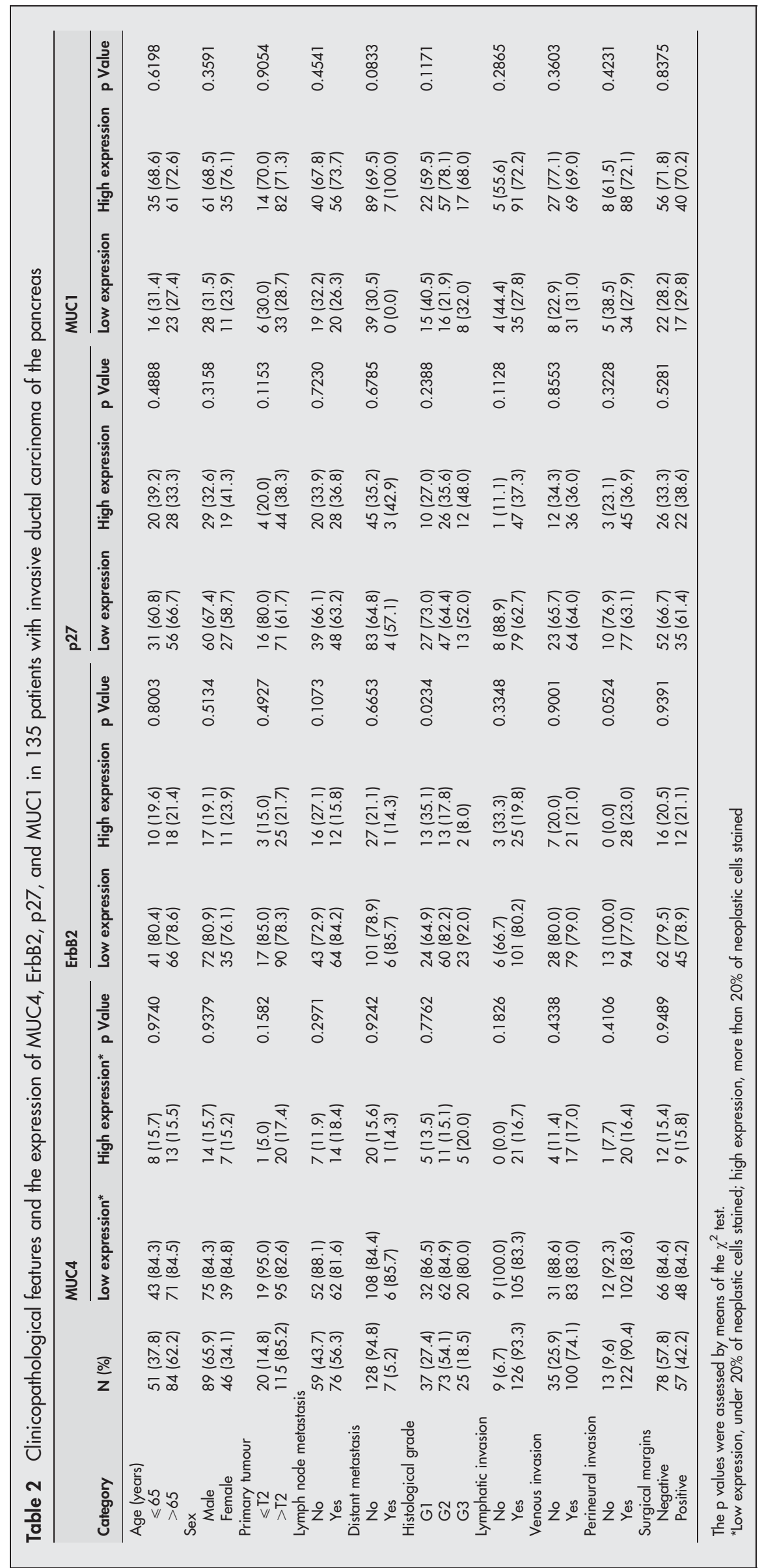



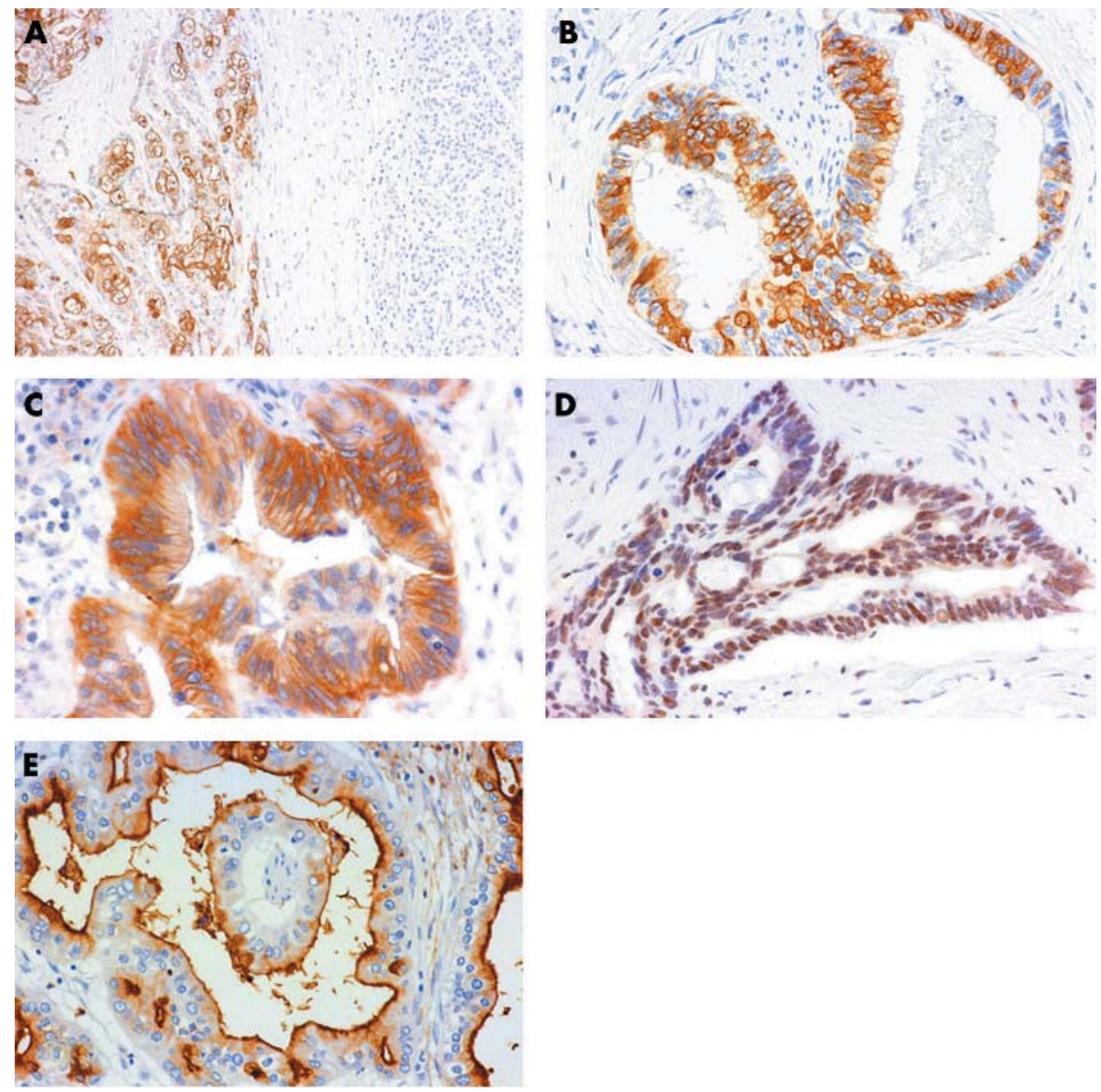

Figure 1 Immunohistochemical staining of (A, B) MUC4, (C) ErbB2, (D) p27, and (E) MUC1 in invasive ductal carcinoma of the pancreas. MUC4 was expressed in the carcinoma tissue (A, left), but not in the normal pancreas tissue (A, right) (original magnification, $\times 40)$. MUC4 expression was seen in the cytoplasm and/or membrane of the carcinoma cells $(B$, original magnification, $\times 160)$. ErbB2 was expressed in the membrane and/or cytoplasm of the carcinoma cells $(C$, original magnification, $\times 160)$. p27 expression was seen in the nuclei of the carcinoma cells $(D$, original magnification, $\times 160)$. MUCl was expressed in the membrane and/or cytoplasm of the carcinoma cells $(E$, original magnification, $\times 160)$.

MUC4, ErbB2, p27, or MUC1 expression profile in IDC Figure 1 shows representative expression patterns of MUC4, ErbB2, p27, and MUC1 in IDC. Positive staining for MUC4

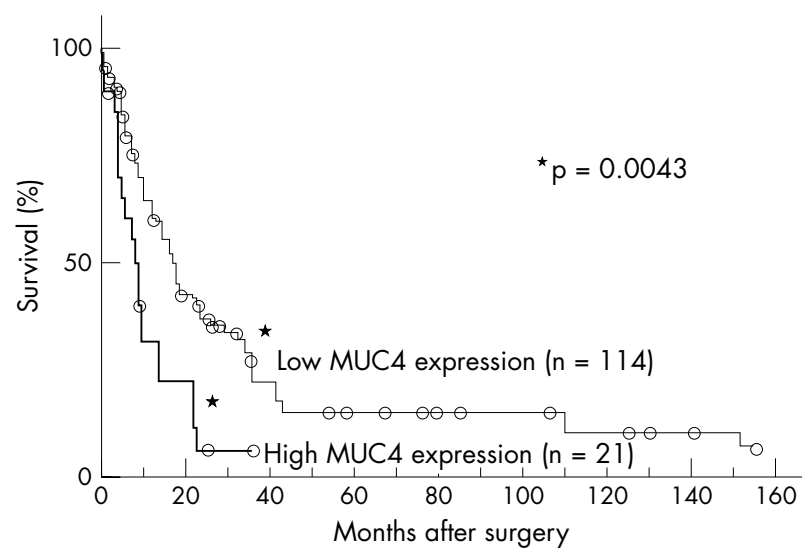

Figure 2 Correlation between MUC4 expression and cumulative survival rate in 135 patients with invasive ductal carcinoma, as determined by the Kaplan-Meier method. The survival of patients with high MUC4 expression was worse than those with low MUC4 expression $(\mathrm{p}=0.0043)$. The open circles represent those patients who were alive at the last follow up. was seen in the cytoplasm and/or membrane of the carcinoma cells in 43 (31.9\%) of 135 IDCs (fig 1A, B).

ErbB2 was expressed at the membrane and/or cytoplasm of the carcinoma cells in $46(34.1 \%)$ of the 135 IDCs (fig 1C), p27 was seen in the nuclei of the carcinoma cells in 62 (45.9\%) (fig 1D), and MUCl was expressed in the membrane and/or cytoplasm of the carcinoma cells in 116 (85.9\%) (fig lE).

\section{Association between MUC4, ErbB2, p27, and MUC1 expression in IDC}

There was no significant association between the expression of MUC4 and the expression of ErbB2, p27, or MUC1 $(\mathrm{p}=0.7595,0.0604$, and 0.5999, respectively; table 1).

\section{Association between expression of MUC4, ErbB2, p27, or MUC1 and clinicopathological features}

Table 2 shows the association between the expression of MUC4, ErbB2, p27, or MUC1 and the clinicopathological features. In the 135 patients examined, 21 (15.6\%) had high MUC4 expression and 114 (84.4\%) had low MUC4 expression. MUC4 expression in IDC was not related to the clinicopathological features listed in table 2. Twenty eight (20.7\%) patients had high ErbB2 expression and 107 (79.3\%) had low ErbB2 expression. The expression of ErbB2 was related to histological grade $(p=0.0234)$. Neither expression of p27 nor MUCl was related to the clinicopathological features listed in table 2 . 


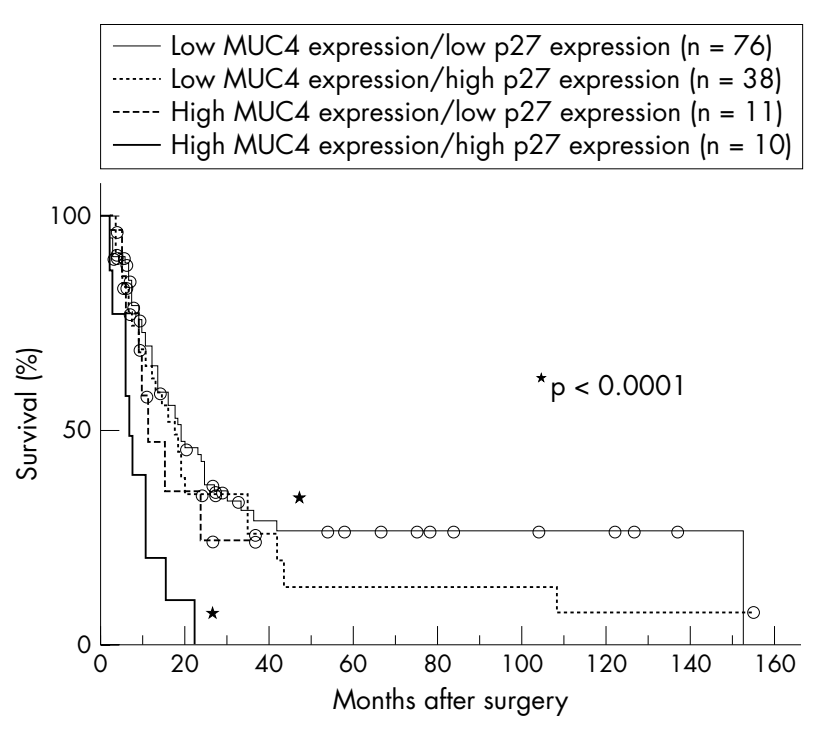

Figure 3 Combined evaluation of MUC4 and p27 expression. Patients with both high MUC4 and p27 expression had the worst outcome. In contrast, patients with both low MUC4 and p27 expression had the best outcome. A significant difference for survival was found between the two groups $(p<0.0001)$. The open circles represent those patients who were alive at the last follow up.

\section{Association between expression of MUC4, ErbB2, p27, MUC1, or histological parameters and cumulative survival rate}

Among the 135 patients examined, 87 died during the follow up period. Forty eight patients were alive at the last follow up and the longest survivor was alive at 155 months after surgery. The overall one, three, and five year survival rates of patients with surgical resection were $58.7 \%, 19.0 \%$, and $11.4 \%$, respectively.

The one, three, and five year survival rates of the high MUC4 expression group were $31.5 \%, 5.6 \%$, and $0.0 \%$, respectively, whereas those of the low MUC4 expression group were $64.2 \%, 22.0 \%$, and $13.9 \%$, respectively. The survival of patients with high MUC4 expression was significantly worse than those with low MUC4 expression $(\mathrm{p}=0.0043 ; \log$ rank test; fig 2$)$. There were no significant associations between survival and the expression of erbB2, p27, or MUCl ( $\mathrm{p}=0.5400,0.0726$, and 0.9730 , respectively; log rank test).

In the combined evaluation of MUC4 and p27 expression, patients with both high MUC4 and p27 expression had a worse outcome than those with both low MUC4 and p27 expression. A significant difference for survival was found between the two groups ( $p<0.0001$; fig 3 ). There was no significant difference in the combined evaluation of MUC4 and ErbB2 expression, or in that of MUC4 and MUC1 expression ( $\mathrm{p}=0.5369$ and 0.0582 , respectively).

The survival of patients with large primary tumour status (> T2), positive distant metastasis, positive lymphatic invasion, or positive surgical margins was significantly worse than those with small primary tumour status $(\leqslant \mathrm{T} 2)$ $(p=0.0089)$, no distant metastasis $(p=0.0292)$, no lymphatic invasion $(\mathrm{p}=0.0156)$, or negative surgical margins $(p=0.0287)(\log$ rank test $)$.

\section{Univariate analysis of prognostic factors}

Table 3 shows the results of univariate analysis of prognostic factors for IDC. MUC4 expression ( $p=0.0061$; hazard ratio (HR), 2.127; 95\% confidence interval (CI), 1.240 to 3.649 ), large primary tumour status $(>\mathrm{T} 2)(\mathrm{p}=0.0436$; HR, 1.846; $95 \%$ CI, 1.018 to 3.350$)$, distant metastasis ( $p=0.0383$; HR,

\begin{tabular}{|c|c|c|c|}
\hline Variable & HR & $95 \% \mathrm{Cl}$ & p Value \\
\hline \multicolumn{4}{|l|}{ Age (years) } \\
\hline$\leqslant 65(n=51)$ & 1 & & \\
\hline$>65(n=84)$ & 1.130 & 0.737 to 1.735 & 0.5749 \\
\hline \multicolumn{4}{|l|}{ Sex } \\
\hline Male $(n=89)$ & 1 & & \\
\hline Female $(n=46)$ & 1.080 & 0.675 to 1.729 & 0.7470 \\
\hline \multicolumn{4}{|l|}{ Primary fumour } \\
\hline$\leqslant T 2(n=20)$ & 1 & & \\
\hline$>T 2(n=11)$ & 1.846 & 1.018 to 3.350 & 0.0436 \\
\hline \multicolumn{4}{|l|}{ Lymph node metastasis } \\
\hline No $(n=59)$ & 1 & & \\
\hline Yes $(n=76)$ & 1.542 & 0.983 to 2.420 & 0.0595 \\
\hline \multicolumn{4}{|l|}{ Distant metastasis } \\
\hline No $(n=128)$ & 1 & & \\
\hline Yes $(n=7)$ & 2.438 & 1.049 to 5.665 & 0.0383 \\
\hline \multicolumn{4}{|l|}{ Histological grade } \\
\hline Gl $(n=37)$ & 1 & & \\
\hline G2 $(n=73)$ & 1.123 & 0.565 to 2.231 & 0.7401 \\
\hline G3 $(n=25)$ & 1.280 & 0.676 to 2.425 & 0.4483 \\
\hline \multicolumn{4}{|l|}{ Lymphatic invasion } \\
\hline No $(n=9)$ & 1 & & \\
\hline Yes $(n=126)$ & 3.208 & 1.163 to 8.846 & 0.0243 \\
\hline \multicolumn{4}{|l|}{ Venous invasion } \\
\hline No $(n=35)$ & 1 & & \\
\hline Yes $(n=100)$ & 1.007 & 0.641 to 1.584 & 0.9745 \\
\hline \multicolumn{4}{|l|}{ Perineural invasion } \\
\hline No $(n=13)$ & 1 & & \\
\hline Yes $(n=122)$ & 1.520 & 0.725 to 3.186 & 0.2673 \\
\hline \multicolumn{4}{|l|}{ Surgical margins } \\
\hline Negative $(n=78)$ & 1 & & \\
\hline Positive $(n=57)$ & 1.608 & 1.038 to 2.490 & 0.0333 \\
\hline \multicolumn{4}{|l|}{ MUC4 expression } \\
\hline Low $(<20 \%)(n=114)$ & 1 & & \\
\hline High $(\geqslant 20 \%)(n=21)$ & 2.127 & 1.240 to 3.649 & 0.0061 \\
\hline \multicolumn{4}{|l|}{ ErbB2 expression } \\
\hline Low $(<20 \%)(n=107)$ & 1 & & \\
\hline High $(\geqslant 20 \%)(n=28)$ & 1.182 & 0.685 to 2.039 & 0.5482 \\
\hline \multicolumn{4}{|l|}{ p27 expression } \\
\hline Low $(<20 \%)(n=87)$ & 1 & & \\
\hline High $(\geqslant 20 \%)(n=48)$ & 1.469 & 0.955 to 2.258 & 0.0798 \\
\hline \multicolumn{4}{|l|}{$\mathrm{MUCl}$ expression } \\
\hline Low $(<20 \%)(n=39)$ & 1 & & \\
\hline High $(\geqslant 20 \%)(n=96)$ & 1.001 & 0.635 to 1.599 & 0.9735 \\
\hline
\end{tabular}

2.438; $95 \%$ CI, 1.049 to 5.665), lymphatic invasion $(\mathrm{p}=0.0243 ; \mathrm{HR}, 3.208 ; 95 \% \mathrm{CI}, 1.163$ to 8.846$)$, and surgical margins ( $\mathrm{p}=0.0333$; HR, $1.608 ; 95 \% \mathrm{CI}, 1.038$ to 2.490) were significant poor risk factors affecting the outcome of the patients.

\section{Multivariate analysis of prognostic factors}

Table 4 shows the results of multivariate analysis of IDC prognostic factors. Among the seven factors selected from the univariate analysis data, based on 0.20 as the cutoff p value, MUC4 expression ( $p=0.0165, \mathrm{HR}, 1.956$; $95 \% \mathrm{CI}, 1.130$ to 3.384) was the only significant poor risk factor affecting the outcome of the patients.

\section{Backward stepwise multivariate analysis of prognostic factors}

Table 5 shows the results of the backward stepwise multivariate analysis of the seven prognostic factors listed in table 4. MUC4 expression ( $\mathrm{p}=0.012 \mathrm{l}$; HR, 2.005; 95\% CI, 1.164 to 3.452$)$, lymph node metastasis $(\mathrm{p}=0.0245$; HR, $1.687 ; 95 \% \mathrm{CI}, 1.069$ to 2.660$)$, and lymphatic invasion $(\mathrm{p}=0.0239 ; \mathrm{HR}, 3.282 ; 95 \% \mathrm{CI}, 1.170$ to 9.207$)$ were significant independent risk factors.

\section{DISCUSSION}

The expression of MUC4 has been studied in IDC tissue samples and cell lines, and its relation to malignant 
Table 4 Multivariate analysis of prognostic factors

\begin{tabular}{|c|c|c|c|}
\hline Variable & HR & $95 \% \mathrm{Cl}$ & p Value \\
\hline \multicolumn{4}{|l|}{ Primary tumour } \\
\hline$\leqslant T 2(n=20)$ & 1 & & \\
\hline$>T 2(n=115)$ & 1.057 & 0.546 to 2.048 & 0.8691 \\
\hline \multicolumn{4}{|l|}{ Lymph node metastasis } \\
\hline No $(n=59)$ & 1 & & \\
\hline Yes $(n=76)$ & 1.547 & 0.955 to 2.507 & 0.0764 \\
\hline \multicolumn{4}{|l|}{ Distant metastasis } \\
\hline No $(n=128)$ & 1 & & \\
\hline Yes $(n=7)$ & 1.532 & 0.641 to 3.664 & 0.3372 \\
\hline \multicolumn{4}{|l|}{ Lymphatic invasion } \\
\hline No $(n=9)$ & 1 & & \\
\hline Yes $(n=126)$ & 2.672 & 0.889 to 8.034 & 0.0801 \\
\hline \multicolumn{4}{|l|}{ Surgical margins } \\
\hline Negative $(n=78)$ & 1 & & \\
\hline Positive $(n=57)$ & 1.372 & 0.880 to 2.140 & 0.1631 \\
\hline \multicolumn{4}{|l|}{ MUC4 expression } \\
\hline Low $(<20 \%)(n=114)$ & 1 & & \\
\hline High $(\geqslant 20 \%)(n=21)$ & 1.956 & 1.130 to 3.384 & 0.0165 \\
\hline \multicolumn{4}{|l|}{ p27 expression } \\
\hline Low $(<20 \%)(n=87)$ & 1 & & \\
\hline High $(\geqslant 20 \%)(n=48)$ & 1.280 & 0.820 to 1.997 & 0.2775 \\
\hline
\end{tabular}

progression has been elucidated. ${ }^{25-28}$ The expression of MUC4 is thought to be a useful indicator of malignancy potential in IDCs, ${ }^{28}{ }^{30}$ but there have been no studies of the direct association between the expression of MUC4 and the outcome of patients with IDC. We have reported that MUC4 expression is a very useful predictor of poor prognosis in patients with ICC-MF: the survival rate of MUC4 positive patients was significantly worse than MUC4 negative patients. $^{32}$

In our present study, we demonstrated for the first time that patients with IDC who have high MUC4 expression had a worse survival rate than those with low MUC4 expression, similar to patients with ICC-MF. Univariate analysis of the prognostic factors in our present study showed that MUC4 expression, primary tumour size, distant metastasis, lymphatic invasion, and surgical margins were significant risk factors affecting the outcome of patients with IDC. Furthermore, MUC4 expression was the only significant prognostic factor for patients with IDC in the multivariate analysis. In the evaluation of independent risk factors using backward stepwise multivariate analysis, MUC4, lymph node metastasis, and lymphatic invasion were significant independent risk factors in patients with IDC. These findings are in line with the progression model for pancreatic adenocarcinoma reported by Swartz et al, showing that MUC4 expression increases with increasing grade of PanIN. ${ }^{30}$

MUC4/sialomucin complex (SMC) is a rat homologue of the human mucin gene MUC4, and its transmembrane subunit acts as an intramembrane ligand for the receptor tyrosine kinase ErbB2 to induce the phosphorylation of the

Table 5 Backward stepwise multivariate analysis of prognostic factors

\begin{tabular}{llll}
\hline Variable & HR & $95 \% \mathrm{Cl}$ & p Value \\
\hline $\begin{array}{l}\text { Lymph node metastasis } \\
\text { No }(n=59)\end{array}$ & 1 & & \\
$\quad \begin{array}{l}\text { Yes }(n=76) \\
\text { Lymphatic invasion }\end{array}$ & 1.687 & 1.069 to 2.660 & 0.0245 \\
$\quad$ No $(n=9)$ \\
$\quad \begin{array}{l}\text { Yes }(n=126) \\
\text { MUC4 expression } \\
\text { Low }(<20 \%)(n=114)\end{array}$ & 1 & & \\
$\quad$ High $(\geqslant 20 \%)(n=21)$ & 2.005 & 1.164 to 3.452 & 0.0121 \\
\hline Cl, confidence interval; HR, hazard ratio. & & \\
\end{tabular}

Tyr-1248 of ErbB2. ${ }^{34}{ }^{36}{ }^{42}$ MUC4/SMC leads to the expression of the cell cycle inhibitor p27. ${ }^{34}$ In addition, MUC4/SMC and neuregulin act synergistically to enhance phosphorylation of both ErbB2 and ErbB3, resulting in the downregulation of p27 and activation of protein kinase B/Akt. ${ }^{35}{ }^{36}$ It is proposed that complex formation between MUC4/SMC and ErbB2 has an effect on epithelial cell behaviour, as a switch in epithelial differentiation and proliferation. ${ }^{35}{ }^{36}$ Furthermore, Singh et al proposed that MUC4 participates in tumour growth and metastasis by directly altering tumour cell properties and/or via modulating ErbB2 expression. ${ }^{43}$ However, in the IDCs examined in our present study, ErbB2 expression was not a significant prognostic factor, and neither was combined MUC4 and ErbB2 expression. Nevertheless, high ErbB2 expression was more frequently seen in well differentiated than in poorly differentiated IDCs. This finding is compatible with a report that that well or moderately differentiated colorectal cancers more frequently express ErbB2 proteins than poorly differentiated tumours. ${ }^{44}$

\section{"Patients with both high MUC4 and p27 expression had a significantly worse outcome than those with both low MUC4 and p27 expression, indicating that p27 upregula- tion is induced by MUC4 expression in invasive ductal carcinoma"}

Low expression of p27 is a poor prognostic factor in gastric cancer, colorectal carcinoma, and intrahepatic cholangiocarcinoma. ${ }^{45-47}$ However, in the IDCs examined in our present study, p27 expression was not an independent prognostic factor, although patients with both high MUC4 and p27 expression had a significantly worse outcome than those with both low MUC4 and p27 expression. This result indicates that p27 upregulation is induced by MUC4 expression in IDC. The relation between p27 upregulation and MUC4 expression may be partly explained by the model proposed by Carraway et al and Jepson et al..$^{35} 36$

MUC4 extends at least $1.12-2.12 \mu \mathrm{m}$ above the cell membrane, far above all other membrane associated proteins, such as adhesion molecules. ${ }^{43}{ }^{48}$ With its rigid and extended structure, MUC4 is thought to be a modulator of cell-cell and cell-extracellular matrix interactions. ${ }^{49}$ Komatsu et al showed that SMC disrupts integrin mediated cell adhesion to extracellular matrix proteins..$^{49}{ }^{50}$ In addition, overexpression of SMC masks the surface antigens on target tumour cells and effectively suppresses tumour cell killing by cytotoxic lymphocytes. ${ }^{49}$ These phenomena may be related to the poor outcome of patients with high MUC4 expression, although MUC4 expression was not related to morphological invasive parameters, such as lymphatic invasion, venous invasion, perineural invasion, and distant lymph node metastasis.

MUCl is also a transmembrane protein, and MUCl expression is related to the development of tumours. ${ }^{5152}$ MUCl expression enhances tumour detachment from the primary site and accelerates distant metastasis, through binding to E selectin and/or intercellular adhesion molecule 1 of the endothelial cells. ${ }^{53-55}$ In previous studies, MUCl expression was related to poor outcome in patients with various carcinomas. ${ }^{18} 323940$ In our previous study of IDC, ${ }^{55}$ MUCl expression was also a poor prognostic factor in advanced cases, although our present study, which includes not only advanced but also early cases, found no relation between the expression of MUCl and the outcome of patients with IDC.

In ICC-MF, MUC4 expression is a more significant prognostic factor than MUCl expression in multivariate analysis. $^{32}$ In ICC-MF, MUCl was expressed at the luminal surface membrane and/or in the cytoplasm, whereas MUC4 


\section{Take home messages}

- The survival of patients with invasive ductal carcinoma (IDC) of the pancreas with high MUC4 expression (>20\% of neoplastic cells stained) was significantly worse than that of those with low MUC4 expression ( $<20 \%$ of neoplastic cells stained)

- Thus, MUC4 expression in IDC is a new independent factor for poor prognosis and predicts the outcome of patients with IDC

expression was seen in the cytoplasm only. In our present study, we confirmed the cytoplasmic expression pattern of MUC4 in IDC also. MUC4 is a membrane mucin, as is MUCl, but MUC4 acts by a different mechanism from that of MUC1. MUCl acts as a docking protein for signalling molecules, whereas MUC4 acts as a receptor ligand. ${ }^{34}$ The different expression patterns of MUCl and MUC4 suggest the possibility of different mechanisms of expression of MUCl and MUC4, both of which are membrane mucins with cell signalling functions.

The combined evaluation of MUC4 and MUCl expression also showed no significant difference in survival for patients with IDC in our present study, although there was a significant difference between MUC4 and MUCl positive patients and MUC4 and MUCl negative patients in ICC-MF. ${ }^{32}$

In conclusion, our results provide new and important information on the importance of MUC4 expression as a useful indicator to predict the outcome of patients with surgically resected IDC. MUC4 has potential as a prognostic marker for clinical management of patients with IDC.

\section{ACKNOWLEDGEMENTS}

We are grateful to Mr Y Atsuji, Ms Y Arimura, and Ms Y Nishimura for their excellent technical assistance. This work was supported by Grants-in-Aid 13220016 (S Yonezawa) and 12218234 (K Imai) from the Ministry of Education, Science, Sports, Culture and Technology, Japan, and USPHS grant CA 78590 from the National Institutes of Health (SK Batra).

\section{Authors' affiliations}

M Saitou, M Goto, S Tamada, K Nagata, T Hamada, S Yonezawa, Department of Human Pathology, Kagoshima University Graduate School of Medical and Dental Sciences, Kagoshima 890-8544, Japan M Horinouchi, Department of Pathology, Kagoshima Medical Association Hospital, 890-0064, Japan

M Osako, Department of Surgery, Kagoshima Medical Association Hospital

S Takao, Research Centre for Life Science Resources, Kagoshima University, Kagoshima 890-8544, Japan

S K Batra, Departments of Biochemistry and Molecular Biology, Eppley Institute for Research in Cancer and Allied Diseases, University of Nebraska Medical Center, Omaha, NE 68198-4525, USA

T Aikou, Surgical Oncology and Digestive Surgery, Field of Oncology, Kagoshima University Graduate School of Medical and Dental Sciences K Imai, Department of Internal Medicine, Sapporo Medical College, Sapporo 060-8556, Japan

\section{REFERENCES}

1 Matsuno S, Egawa S, Fukuyama S, et al. Pancreatic cancer registry in Japan: 20 years of experience. Pancreas 2004;28:219-30.

2 Isaji S, Kawarada Y, Uemoto S. Classification of pancreatic cancer: comparison of Japanese and UICC classifications. Pancreas 2004;28:231-4

3 Egawa S, Takeda K, Fukuyama S, et al. Clinicopathological aspects of small pancreatic cancer. Pancreas 2004;28:235-40.

4 Yonezawa S, Sato E. Expression of mucin antigens in human cancers and its relationship with malignancy potential. Pathol Int 1997;47:813-30.

5 D'Cruz OJ, Dunn TS, Pichan P, et al. Antigenic cross-reactivity of human tracheal mucin with human sperm and trophoblasts correlates with the expression of mucin 8 gene messenger ribonucleic acid in reproductive tract tissues. Fertil Steril 1996;66:316-26.

6 Lapensee L, Paquette Y, Bleav, G. Allelic polymorphism and chromosomal localization of the human oviductin gene (MUC9). Fertil Steril 1997:68:702-8.

7 Williams SJ, McGuckin MA, Gotley DC, et al. Two novel mucin genes downregulated in colorectal cancer identified by differential display. Cancer Res 1999;59:4083-9

8 Williams SJ, Wreschner DH, Tran M, et al. Muc13, a novel human cell surface mucin expressed by epithelial and hemopoietic cells. J Biol Chem 2001 ;276: 18327-36.

9 Pallesen LT, Berglund L, Rasmussen LK, et al. Isolation and characterization of MUC15, a novel cell membrane-associated mucin. Eur J Biochem 2002;269:2755-63

10 Yin BW, Dnistrian A, Lloyd KO. Ovarian cancer antigen CA1 25 is encoded by the MUC16 mucin gene. Int J Cancer 2002;98:737-40.

11 Gum JR Jr, Crawley SC, Hicks JW, et al. MUC17, a novel membrane-tethered mucin. Biochem Biophys Res Commun 2002;291:466-75.

12 Moniaux N, Escande F, Porchet N, et al. Structural organization and classification of the human mucin genes. Front Biosci 2001;6:D1 192-206.

13 Yonezawa S, Nakamura A, Horinouchi $M$, et al. The expression of several types of mucin is related to the biological behavior of pancreatic neoplasms. J Hepatobiliary Pancreat Surg 2002;9:328-41.

14 Tamada S, Goto M, Nomoto M, et al. Expression of MUC1 and MUC2 mucins in extrahepatic bile duct carcinomas: its relationship with tumor progression and prognosis. Pathol Int 2002;52:713-23.

15 Nakamura A, Horinouchi M, Goto M, et al. New classification of pancreatic intraductal papillary-mucinous tumour by mucin expression: its relationship with potential for malignancy. J Pathol 2002;197:201-10.

16 Utsunomiya T, Yonezawa S, Sakamoto $\mathrm{H}$, et al. Expression of $\mathrm{MUCl}$ and MUC2 mucins in gastric carcinomas: its relationship with the prognosis of the patients. Clin Cancer Res 1998;4:2605-14.

17 Higashi M, Yonezawa S, Ho JJ, et al. Expression of MUC1 and MUC2 mucin antigens in intrahepatic bile duct tumors: its relationship with a new morphological classification of cholangiocarcinoma. Hepatology 1999;30:1347-55

18 Sagara M, Yonezawa S, Nagata K, et al. Expression of mucin 1 (MUC1) in esophageal squamous-cell carcinoma: its relationship with prognosis. Int J Cancer 1999:84:251-7.

19 Horinouchi M, Nagata K, Nakamura A, et al. Expression of different glycoforms of membrane mucin (MUC1) and secretory mucin (MUC2, MUC5AC and MUC6) in pancreatic neoplasms. Acta Histochem Cytochem 2003;36:443-53.

20 Porchet N, Nguyen VC, Dufosse J, et al. Molecular cloning and chromosomal localization of a novel human tracheo-bronchial mucin cDNA containing tandemly repeated sequences of 48 base pairs. Biochem Biophys Res Commun 1991; 175:414-22.

21 Buisine MP, Devisme L, Copin MC, et al. Developmental mucin gene expression in the human respiratory tract. Am J Respir Cell Mol Biol 1999;20:209-18

22 Audie JP, Janin A, Porchet N, et al. Expression of human mucin genes in respiratory, digestive, and reproductive tracts ascertained by in situ hybridization. J Histochem Cytochem 1993;41:1479-85.

23 Audie JP, Tetaert D, Pigny $P$, et al. Mucin gene expression in the human endocervix. Hum Reprod 1995;10:98-102.

24 Gipson IK, Spurr-Michaud S, Moccia R, et al. MUC4 and MUC5B transcripts are the prevalent mucin messenger ribonucleic acids of the human endocervix. Biol Reprod 1999;60:58-64.

25 Hollingsworth MA, Strawhecker JM, Caffrey TC, et al. Expression of MUC1 MUC2, MUC3 and MUC4 mucin mRNAs in human pancreatic and intestinal tumor cell lines. Int J Cancer 1994;57:198-203.

26 Balague C, Gambus G, Carrato C, et al. Altered expression of MUC2, MUC4, and MUC5 mucin genes in pancreas tissues and cancer cell lines. Gastroenterology 1994;106:1054-61.

27 Balague C, Audie JP, Porchet N, et al. In situ hybridization shows distinct patterns of mucin gene expression in normal, benign, and malignant pancreas tissues. Gastroenterology 1995; 109:953-64

28 Andrianifahanana M, Moniaux N, Schmied BM, et al. Mucin (MUC) gene expression in human pancreatic adenocarcinoma and chronic pancreatitis: a potential role of MUC4 as a tumor marker of diagnostic significance. Clin Cancer Res 2001;7:4033-40.

29 Hruban RH, Adsay NV, Albores-Saavedra J, et al. Pancreatic intraepithelial neoplasia: a new nomenclature and classification system for pancreatic duct lesions. Am J Surg Pathol 2001;25:579-86.

30 Swartz MJ, Batra SK, Varshney GC, et al. MUC4 expression increases progressively in pancreatic intraepithelial neoplasia. Am J Clin Pathol 2002;117:791-6

31 Vandenhaute B, Buisine MP, Debailleul V, et al. Mucin gene expression in biliary epithelial cells. J Hepatol 1997;27:1057-66.

32 Shibahara $H$, Tamada S, Higashi M, et al. MUC4 is a novel prognostic factor of intrahepatic cholangiocarcinoma-mass forming type. Hepatology 2004;39:220-9.

33 Carraway KL 3rd, Rossi EA, Komatsu M, et al. An intramembrane modulator of the ErbB2 receptor tyrosine kinase that potentiates neuregulin signaling. J Biol Chem 1999;274:5263-6.

34 Ramsaver VP, Carraway CA, Salas PJ, et al. Muc4/sialomucin complex, the intramembrane ErbB2 ligand, translocates ErbB2 to the apical surface in polarized epithelial cells. J Biol Chem 2003;278:30142-7.

35 Carraway KL, Ramsauer VP, Haq B, et al. Cell signaling through membrane mucins. Bioessays 2003;25:66-71. 
36 Jepson S, Komatsu M, Haq B, et al. Muc4/sialomucin complex, the intramembrane ErbB2 ligand, induces specific phosphorylation of ErbB2 and enhances expression of p27(kip), but does not activate mitogen-activated kinase or protein kinaseB/Akt pathways. Oncogene $2002 \cdot 21 \cdot 7524-32$

37 Polyak K, Kato JY, Solomon MJ, et al. p27Kipl, a cyclin-Cdk inhibitor, links transforming growth factor-beta and contact inhibition to cell cycle arrest. Genes Dev 1994;8:9-22.

38 Ito $Y$, Takeda T, Sakon M, et al. Expression and clinical significance of the G1-S modulators in carcinoma of the extrahepatic bile duct. Anticancer Res 2000;20:337-44.

39 Matsumura N, Yamamoto M, Aruga A, et al. Correlation between expression of $\mathrm{MUCl}$ core protein and outcome after surgery in mass-forming intrahepatic cholangiocarcinoma. Cancer 2002;94:1770-6.

40 Takao S, Uchikura K, Yonezawa S, et al. Mucin core protein expression in extrahepatic bile duct carcinoma is associated with metastases to the liver and poor prognosis. Cancer 1999;86:1966-75.

41 Wittekind C, Compton CC, Greene FL, et al. TNM residual tumor classification revisited. Cancer 2002:94:2511-16.

42 DiGiovanna MP, Stern DF. Activation state-specific monoclonal antibody detects tyrosine phosphorylated p185neu/erbB-2 in a subset of human breast tumors overexpressing this receptor. Cancer Res 1995:55:1946-55.

43 Singh AP, Moniaux N, Chauhan SC, et al. Inhibition of MUC4 expression suppresses pancreatic tumor cell growth and metastasis. Cancer Res 2004;64:622-30

44 Half E, Broaddus R, Danenberg KD, et al. HER-2 receptor expression, localization, and activation in colorectal cancer cell lines and human tumors. Int J Cancer 2004;108:540-8.
45 Sgambato A, Migaldi $M$, Leocata $P$, et al. Loss of $p 27$ Kipl expression is a strong independent prognostic factor of reduced survival in NO gastric carcinomas. Cancer 2000;89:2247-57.

46 Chen AJ, Meng QH, Long B, et al. (Relationship between p27 expression and prognosis of colorectal carcinoma.) Ai Zheng 2002;21:1075-7.

47 Taguchi K, Aishima S, Asayama Y, et al. The role of p27kipl protein expression on the biological behavior of intrahepatic cholangiocarcinoma. Hepatology 2001;33:1 118-23

48 Moniaux N, Nollet S, Porchet N, et al. Complete sequence of the human mucin MUC4: a putative cell membrane-associated mucin. Biochem J 1999;338:325-33

49 Komatsu M, Yee L, Carraway KL. Overexpression of sialomucin complex, a rat homologue of MUC4, inhibits tumor killing by lymphokine-activated killer cells. Cancer Res 1999:59:2229-36.

50 Komatsu M, Carraway CA, Fregien NL, et al. Reversible disruption of cellmatrix and cell-cell interactions by overexpression of sialomucin complex. J Biol Chem 1997;272:33245-54.

51 Brayman M, Thathiah A, Carson DD. MUC1: a multifunctional cell surface component of reproductive tissue epithelia. Reprod Biol Endocrinol 2004:2:4.

52 Levi E, Klimstra DS, Adsay NV, et al. MUC1 and MUC2 in pancreatic neoplasia. J Clin Pathol 2004;57:456-62.

53 McDermott KM, Crocker PR, Harris A, et al. Overexpression of MUC1 reconfigures the binding properties of tumor cells. Int J Cancer 2001;94:783-91.

54 Kam JL, Regimbald LH, Hilgers JH, et al. MUC1 synthetic peptide inhibition of intercellular adhesion molecule- 1 and $\mathrm{MUC1}$ binding requires six tandem repeats. Cancer Res 1998;58:5577-81.

55 Hinoda $Y$, Ikematsu $Y$, Horinochi $M$, et al. Increased expression of $M U C 1$ in advanced pancreatic cancer. J Gastroenterol 2003;38:1162-6.

\section{$\mathrm{ECHO}$}

\section{Postmortems on very preterm infants are valuable}

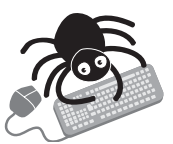

Please visit the Journal of Clinical

Pathology website [www. jclinpath.com] for a link to the full text of this article. ostmortem examinations on very premature infants are valuable to help doctors to understand and accept the certainty of death in certain circumstances and to help them advise parents, according to a small study. They may also help in future prognoses, and their findings may lead changes in intensive care policies and protocols.

Postmortem examinations on 29 infants of $<28$ weeks' gestation who died in intensive care within 28 days after their birth resulted in new diagnoses in no less than $79 \%$ and significant change in diagnosis in $28 \%$, when compared with the clinical diagnosis. Injuries caused by treatment were evident in $41 \%$ of the group and were considered to be the main cause of death in 4\% (four infants). Elsewhere published rates are 4-15\%. Some deaths were due to complications of extreme prematurity such as lung disease, but complications of pregnancy or labour also featured.

The examinations were performed by an experienced perinatal pathologist at a major paediatric centre in New Zealand on 29 of 54 infants meeting the criteria who died during January 1995-December 2003.

Extreme prematurity can be given as the cause of death on the death certificate when extremely preterm infants die, but this tells us little and does not advance our knowledge, especially as infants this young are less likely to have postmortem examinations anyway.

A Elder DE, et al. Archives of Disease in Childhood Fetal and Neonatal Edition 2005;90:F270-F272. 